\title{
Transfer Passengers' Perceptions of Airport Service Quality: A Case Study of Incheon International Airport
}

\author{
Jin-Woo, Park (Corresponding author) \\ Assistant Professor, Department of Business Administration, Korea Aerospace University \\ 200-1, Hwajeon-dong, Deokyang-gu, Goyang-city, Gyeonggi-do, 421-791, South Korea \\ Tel: 82-2-300-0354Ｅ-mail:jwpark@kau.ac.kr \\ Se-Yeon, Jung \\ Master's student, Department of Business Administration, Korea Aerospace University \\ 200-1, Hwajeon-dong, Deokyang-gu, Goyang-city, Gyeonggi-do, 421-791, South Korea \\ Tel: 82-10-6795-6566 E-mail:jsy@kau.ac.kr
}

Received: February 14, 2011 Accepted: February 26, 2011 doi:10.5539/ibr.v4n3p75

\begin{abstract}
This paper seeks to investigate transfer passenger's perception of airport service quality and its influence on value, satisfaction, airport image, and passenger behavior. To test the relationships between the variables, Structural Equation modeling is used to analyze survey data collected from 331 transfer passengers at Incheon International Airport. The results show that airport service quality would raise the level of transfer passengers' satisfaction, value perceptions, and airport image formation. In addition, airport service quality has an indirect impact on transfer passenger behavior by means of value, satisfaction, and airport image.
\end{abstract}

Keywords: Airport service quality, Transfer passenger, Structural equation modeling

\section{Introduction}

Airport passengers can be divided into different groups such as departing, arriving and transfer passengers. Each of these groups will have a different set of needs and wishes when they use different facilities at the airport. For example, transfer passengers have discretionary time waiting and they will likely to value their experience in airport facilities differently compared to origin and destination passengers.(Anderson et al., 2008) The needs of transfer passengers are quite different from those of origin and destination passengers.(de Barros et al., 2007) After deregulation and privatization, many large international airports have served as hubs for transfer passengers therefore the importance of transfer passengers have been increased. Thus, understanding and catering for the specific needs of transfer passengers are fundamental in achieving growth in today's competitive airport environment.

Here the effect of airport service quality on the transfer passenger traffic of Incheon International Airport (IIA) is explored by examining a conceptual model that considers airport service quality as well as a number of other factors that simultaneously influence transfer passenger's behavior.

\section{Conceptual background}

\subsection{Service quality}

Service quality is customer's long-term, cognitive evaluations of a firm's service delivery. Customers compare what they expect to get with what they actually receive during the postpurchase stage of the service purchase process. Before customers purchase a service, they have an expectation about service quality that is based on individual needs, past experiences, word-of-mouth recommendations, and a service provider's advertising. After buying and consuming the service, customers compare its expected quality with what they actually received.(Lovelock \&. Wright, 1999) A frequently used and highly debated measure of service quality is the SERVQUAL scale. According to its developers, SERVQUAL is a diagnostic tool that uncovers a firm's broad weaknesses and strengths in the area of service quality. The SERVQIAL instrument is based on five service quality dimensions that were obtained through extensive focus group interviews with consumers. The five dimensions include tangibles, reliability, responsiveness, assurance, and empathy, and they provide the basic skeleton underlying service quality.(Hoffman $\&$ Bateson, 2001) 
Delivering high service quality has been recognized as the most efficient way of ensuring that a company's offerings are uniquely positioned in a market filled with lookalike competitive offerings.(Parasuraman et al., 1991) Improving the quality of manufactured goods has become a major strategy for both establishing efficient, smoothly running operations and increasing demanding higher and higher quality.(Hoffman \&Bateson, 2001) Providing high quality service and ensuring customer satisfaction are widely recognized as important factors leading to the success of the various service industries.(Stevens et al., 1995) It is commonly believed that higher service quality can lead to a customer's higher overall satisfaction and subsequently to positive behavioral intentions. Like other service industries, service quality is an important issue in the airport management. The overall airport's experience perceived and recollected by international travellers may have a significant impact in promoting or discouraging future international tourism and business activities in the corresponding country. Thus, the evaluation of passenger satisfaction levels on airport services has become an important issue for airport management.(Yeh \& Kuo, 2003)

\subsection{Customer satisfaction and loyalty}

Customers experience various level of satisfaction or dissatisfaction after each service experience according to the extent to which their expectations were met or exceeded. Because satisfaction is an emotional state, their postpurchase reactions can involve anger, dissatisfaction, irritation, neutrality, pleasure, or delight.(Lovelock \&. Wright, 1999) The importance of customer satisfaction cannot be overstated. Without customers the service firm has no reason to exist. Every service business needs to proactively define and measure customer satisfaction. Companies who command high customer satisfaction ratings seem to have the ability to insulate themselves from competitive pressures, particularly price competition.(Hoffman \& Bateson, 2001)

Past research studies have suggested that perceptions of service quality affect feelings of satisfaction, which then affect loyalty and post-purchase behaviors.(Anderson, 1993) Satisfaction is perceived as being an important mediator of store loyalty drivers.(Taylor \& Baker, 1994) Customer satisfaction has always been considered an essential business goal because it was assumed that satisfied customers would buy more.(Oliver, 1999) Recently, the evaluation of passenger satisfaction levels on airport services has become an important issue for airport management to understand their consumers and in designing their marketing strategies. (Yeh \& Kuo, 2003)

\subsection{Service value and image}

The general definition of value is a consumer's perception of the subjective worth of some activity or object considering all net benefits and costs of consumption.(Babin et al., 1994) Service value has been identified as an important variable of customer satisfaction and behavioral intentions.(McDougall \& Levesque, 2000)

Corporate image is described as the overall impression made on the minds of the public about a firm.(Barich \& Kotler, 1991) Image is a perception of an organization held in consumer memory which influences the perception of the operation of the company (Grönroos, 1988) also it is another important factor in the overall service evaluation.(Gummesson \& Grönroos, 1988) Image is based on all of a customer's consumption experiences, and service quality is representative of these consumption experiences. Hence, the perception of service quality directly affects the perception of image. (Aydin \& Ozer, 2005)

\subsection{The trend of Incheon International Airport (IIA)}

The trends of de-regulation and privatization in air transportation over the past three decades have led to increasingly globalized hub-and-spoke networks of airports. This trend has also been observed in many large international airports including IIA, which serve as hubs for transfer passengers between international flights.(de Barros el al., 2007) The largest airport in South Korea, IIA is one of the largest and busiest in the world and it has been consecutively rated as the best airport in the world by the Airports Council International (ACI) since 2005. One of the significant strategies of IIA is to be an international hub in Northeast Asia therefore transfer passengers are one of the most important factors for airport management. Since 2005, the number of transfer passengers at IIA has increased an average of $10.5 \%$ and the airport devises a strategy to increase the proportion of transfer passengers up to $25 \%$ by 2010 (Figure 1). Because the airport tries to increase transfer rate and passengers to be a hub airport, understanding the needs of transfer passengers has become a significant aspect for IIA.

$<$ Insert Figure 1 here >

To increase the number of transfer passengers by delivering better services, airport managers need to understand passenger perceptions of airport service quality. To investigate transfer passenger's perception of airport service quality and its influence, the hypotheses to be tested empirically are shown as arrows. All the paths are hypothesized to be positive (Table 2).

$<$ Insert Figure 2 here $>$ 


\section{Research Methodology}

The survey was conducted at the airside of IIA in November 2009. The questionnaire was translated into English, Chinese, and Japanese since majority of transfer passengers at IIA is an English, Chinese, and Japanese-speaking people. A total of 400 questionnaires were distributed to transfer passengers at the transfer passenger lounges, transfer hotels, and gates. Some 360 completed questionnaires were collected, but 29 questionnaires were incomplete, leaving 331 samples for data analysis. Survey samples are shown well distributed in terms of nationality.

The design of the questionnaire is based on multiple-item measurement scales. The measurement items are designed for the airport and the statements are measured on a 5-point Likert-type scale. Five constructs are included in the hypotheses that are tested. They are: airport service quality, value, transfer passenger satisfaction, airport image, and transfer passenger behavior.

SERVQUAL is a survey instrument that purports to measure the quality of service rendered by institution along five dimensions: reliability, assurance, tangibles, empathy and responsiveness.(Parasuraman el al., 1985) The transfer passengers' perceptions of airport service quality are quite various and do not seem to fit any single existing service quality model such as SERVQUAL. This is because SERVQUAL instrument does not address other important aspects of airport service such as walking distance, walking facilities, and duty free shops. Therefore, this study evaluates airport service quality based on SERVQUAL but has developed specific questions and dimensions that are suitable for airports by modifying and adding new items important.

Airport service quality is measured by 22 measurement items listed in Table 1. Exploratory factor analysis is used to determine the dimension of airport service quality. The overall pattern of rotated factor loadings suggests a three-dimensional solution (Table 2). Airport service quality is measured by three observed variables, namely X1, $\mathrm{X} 2$, X3. Each of these variables is calculated as the mean score of respondents' ratings of each item in the each factor. Reliability of measures is assessed using Cronbach's alpha; the resultant alpha is more than 0.7 that implying a good level of reliability.

$<$ InsertTable 1 here $>$

$<$ Insert Table 2 here $>$

\section{Data analysis and results}

To assess the fit of the model, Goodness-of-Fit Index (GFI), Adjusted Goodness-of-fit index (AGFI), Normed fit index (NFI), Root mean square residual (RMR), and Root mean square error of approximation (RMSEA) are used in this paper (Table 3). The various fitness indexes for the model indicate that the theoretical model indicates an excellent fit. The proposed conceptual model explains a substantial amount of variance in key variables. The model explains $77.8 \%$ of variance in transfer passenger behavior and $65.7 \%$ of variance in airport image. The model also explains $73.9 \%$ of variance in value and $82.1 \%$ of variance in transfer passenger satisfaction. The conceptual model is tenable in that the amount of variance explained in most variables exhibits a high practical significance.

$<$ Insert Figure 3 here $>$

All the hypothesized relationships are statistically significant $(\mathrm{p}<0.05)$. Airport service quality is found to have a significant positive effect on value, satisfaction, and airport image. The result of figure 3 indicates that airport service quality is a key driver of transfer passenger's value perception, level of satisfaction, and airport image formation. The analysis also shows that airport service quality has a positive influence on transfer passenger behavior through value, satisfaction, and airport image. The analysis indicates that airport service quality influences transfer passengers' reuse intentions and the intention to recommend the airport to other transfer passengers indirectly by means of value, satisfaction, and airport image. Value and airport image are each found to have a direct effect on transfer passenger satisfaction and behavior. This finding implies that if transfer passengers think they are getting high value from the airport services they receive, they are more likely to be satisfied, to use the airport again, and to recommend the airport to other transfer passengers. This result also implies that transfer passengers who form a positive overall impression of the airport are more likely to use the airport again and recommend the airport to others for transfer. Transfer passenger satisfaction is found to have a positive effect on transfer passenger behavior. This suggests that transfer passengers satisfied by airport services are more likely to reuse the airport and recommend the airport to others.

\section{Conclusion}

This paper has presented a conceptual model of airport service quality with value, transfer passenger satisfaction, airport image, and transfer passenger behavior. The analysis shows that airport service quality is found to have a direct or an indirect effect on value, satisfaction, airport image, and passenger behavior. The results from a study of transfer passengers imply a need for IIA to develop transfer passenger-focused services to increase transfer 
passengers. Failure to provide quality services to transfer passengers may damage the level of satisfaction, value perceptions, and the formation of airport image and cause negative impact on transfer passenger behavior.

\section{Acknowledgements}

The co-operation of Incheon International Airport for the survey of this study is very much appreciated by the authors. The authors also extend our thanks to the survey team for their support to distribute and collect survey questionnaires at the airport.

\section{References}

Anderson, E., W. Sullivan, M. W. (1993). The antecedents and consequences of customer satisfaction for firms. Marketing Science. 12(2), 125-143, doi:10.1287/mksc.12.2.125, http://dx.doi.org/10.1287/mksc.12.2.125

Aydin, S. Ozer, G. (2005).The analysis of antecedents of customer loyalty in Turkish mobile telecommunication market. European Journal of Marketing. 39(7/8), 910-925, doi:10.1108/03090560510601833, http://dx.doi.org/10.1108/03090560510601833

Babin, B.J., Darden, W.R., \& Griffin, M. (1994). Work and/or fun Measuring hedonic and utilitarian shopping value. Journal of Consumer Research. 20(4), 644-656, doi:10.1086/209376, http://dx.doi.org/10.1086/209376

Barich, H. Kotler, P. (1991). A framework for marketing image management. Sloan Management Review. 32(2), 94-104.

Correia, A.R., Wirasinghe, S.C., \& de Barros, A.G. (2008). A global index for level of service evaluation at airport. Transportation Research Part E. 44(4), 607-620, doi:10.1016/j.tre.2007.05.009, http://dx.doi.org/10.1016/j.tre.2007.05.009

de Barros, A.G., Somasundaraswaran, A.K., \& Wirasinghe, S.C. (2007). Evaluation of level of service for transfer passengers at airports. Journal of Air Transport Management. 13(5), 293-298.

Grönroos, C. (1988). Service quality: the six criteria of good perceived service quality. Rev Bus. 9(3), 10-13.

Gummesson, E. Grönroos, C. (1988). Quality of services: lessons from the product sector. Add value to your service. Chicago: American Marketing Association.

Horonjeff, R. McKelvey, F.X. (1994). Planning and Design of Airport. (4th ed.). New York: McGraw-Hill.

Hoffman, K. D., Bateson John E. G. (2001). Essentials of services marketing: concepts,strategies, \&cases. (2nd ed.). South-Western:Thomson Learning,(Chapter 12-13).

Incheon International Airport, (2009). Incheon International Airport annual report. Incheon, pp.14-15: http://www.airport.kr/iiacms/pageWork.iia?_scode=C2405020402(March 3,2010)

Lovelock, Christopher H. Wright, Lauren K. (1999). Principles of service marketing and management. New Jersey: Prentice-Hall,(Chapter 5).

McDougall, G.H. Levesque, T. (2000). Customer satisfaction with services: putting perceived value into the equation. Journal of Service Marketing. 14(5), 392-410, doi:10.1108/08876040010340937, http://dx.doi.org/10.1108/08876040010340937

Oliver, R. L. (1999). Whence consumer loyalty. Journal of Marketing. 63, 33-44, doi:10.2307/1252099, http://dx.doi.org/10.2307/1252099

Parasuraman, A., Zeithaml, V.A., \& Berry, L.L. (1985). SERVQUAL: A multiple-item scale for measuring consumer perceptions of service quality. Journal of Retailing. 64, 12-40.

Parasuraman, A., Zeithaml, V.A., \& Berry, L.L. (1991). Refinement and reassessment of the SERVQUAL scale. Journal of Retailing. 64(4), 420-450.

Stevens, P., Knutson, B., \& Patton, M. (1995). A tool for measuring service quality in restaurants. Cornell Hotel and Restaurant Administration Quarterly, 36(2), 56-60, doi:10.1016/0010-8804(95)93844-K, http://dx.doi.org/10.1016/0010-8804(95)93844-K

Taylor, S.A. Baker, T.L. (1994). An assessment of the relationship between service quality and customer satisfaction in the formation of consumers' purchase intentions. Journal of Retailing. 70(2), 163-178, doi:10.1016/0022-4359(94)90013-2, http://dx.doi.org/10.1016/0022-4359(94)90013-2

Yeh, C.H. Kuo, Y.L. (2003). Evaluating passenger services of Asia-Pacific international airports. Transportation Research Part E. 39(1), 35-48, doi:10.1016/S1366-5545(02)00017-0, http://dx.doi.org/10.1016/S1366-5545(02)00017-0 
Table 1. Airport service quality measurement items

\begin{tabular}{|c|c|}
\hline Measures & Variables \\
\hline \multirow{22}{*}{ Service Quality } & Transfer terminal's modernity facilities and cleanliness \\
\hline & Transfer terminal's atmosphere/comfort \\
\hline & Enough available seats in transfer area \\
\hline & Flight information display \\
\hline & On-time performance \\
\hline & Giving service without delay \\
\hline & Employees who are willing to help passengers \\
\hline & Employees who sincere interest in solving problems \\
\hline & Reliability of employees \\
\hline & Safety of transfer terminal \\
\hline & Courtesy of employees \\
\hline & Employees who have the knowledge to answer about transfer passengers' questions \\
\hline & Giving transfer passengers personal attention \\
\hline & Understanding transfer passengers' needs \\
\hline & Walking distance/walking time \\
\hline & Walking facilities (escalators/elevators/moving walkways) \\
\hline & Restaurants and bars quality \\
\hline & Restaurants and bars variety/price \\
\hline & Duty free shops' price compared to other countries \\
\hline & Duty free shops' availability of goods/variety \\
\hline & Children's play areas \\
\hline & Medicine/pharmacy \\
\hline
\end{tabular}

The table describes the list of 22 items of service quality measurement.

Table 2. Results of factor analysis

\begin{tabular}{|c|c|c|c|c|}
\hline Factor & Variables & $\begin{array}{c}\text { Factor } \\
\text { loadings }\end{array}$ & Eigenvlaue & $\begin{array}{l}\text { Cummulative } \\
\% \text { of variance }\end{array}$ \\
\hline \multirow{11}{*}{$\begin{array}{c}\text { Factor } 1 \\
(\mathrm{X} 1)\end{array}$} & Courtesy of employees & .753 & \multirow{11}{*}{10.873} & \multirow{11}{*}{49.424} \\
\hline & Safety of transfer terminal & .743 & & \\
\hline & Reliability of employees & .725 & & \\
\hline & Employees who sincere interest in solving problems & .725 & & \\
\hline & Employees who are willing to help passengers & .718 & & \\
\hline & $\begin{array}{l}\text { Employees who have the knowledge to answer about } \\
\text { transfer passengers' questions }\end{array}$ & .707 & & \\
\hline & Giving transfer passengers personal attention & .707 & & \\
\hline & Giving service without delay & .671 & & \\
\hline & On-time performance & .656 & & \\
\hline & Understanding transfer passengers' needs & .633 & & \\
\hline & Flight information display & .516 & & \\
\hline \multirow{7}{*}{$\begin{array}{c}\text { Factor } 2 \\
(\mathrm{X} 2)\end{array}$} & Children's play areas & .796 & \multirow{7}{*}{1.923} & \multirow{7}{*}{58.166} \\
\hline & Restaurants and Bars variety/price & .787 & & \\
\hline & Duty free shops' price compared to other countries & .786 & & \\
\hline & Medicine/pharmacy & .781 & & \\
\hline & Duty free shops' availability of goods/variety & .724 & & \\
\hline & Restaurants and bars quality & .667 & & \\
\hline & Walking distance/walking time & .600 & & \\
\hline \multirow{4}{*}{$\begin{array}{c}\text { Factor } 3 \\
(\mathrm{X} 3)\end{array}$} & Transfer terminal's atmosphere/comfort & .724 & \multirow{4}{*}{1.097} & \multirow{4}{*}{63.152} \\
\hline & Transfer terminal's modernity facilities and cleanliness & .711 & & \\
\hline & Enough available seats in transfer area & .585 & & \\
\hline & Walking facilities (escalators/elevators/moving walkways) & .505 & & \\
\hline
\end{tabular}

As a result of exploratory factor analysis, the factor loadings suggest a three-dimensional solution. Airport service quality is measured by three observed variables, namely X1, X2, X3. Factor loading were used to assign a name to each factor. 
Table 3. Goodness-of-fit measures

\begin{tabular}{|l|l|}
\hline Goodness-of-fit measure & Value \\
\hline Chi-square value $\left(\mathrm{x}^{2}\right)$ & 137.936 \\
\hline Degrees of freedom(DF) & 46 \\
\hline Chi-square value $\left(\mathrm{x}^{2}\right)$ /degrees of freedom(DF) & 2.99 \\
\hline P-value & 0.000 \\
\hline Goodness-of-fit index(GFI) & 0.936 \\
\hline Adjusted goodness-of-fit index(AGFI) & 0.891 \\
\hline Normed fit index(NFI) & 0.956 \\
\hline Root mean square residual(RMR) & 0.024 \\
\hline Root mean square error of approximation(RMSEA) & 0.078 \\
\hline
\end{tabular}

The SEM analysis provided evidence of a good model fit. Given the satisfactory fit of the model, the estimated structural coefficients were then examined to evaluate the hypotheses.

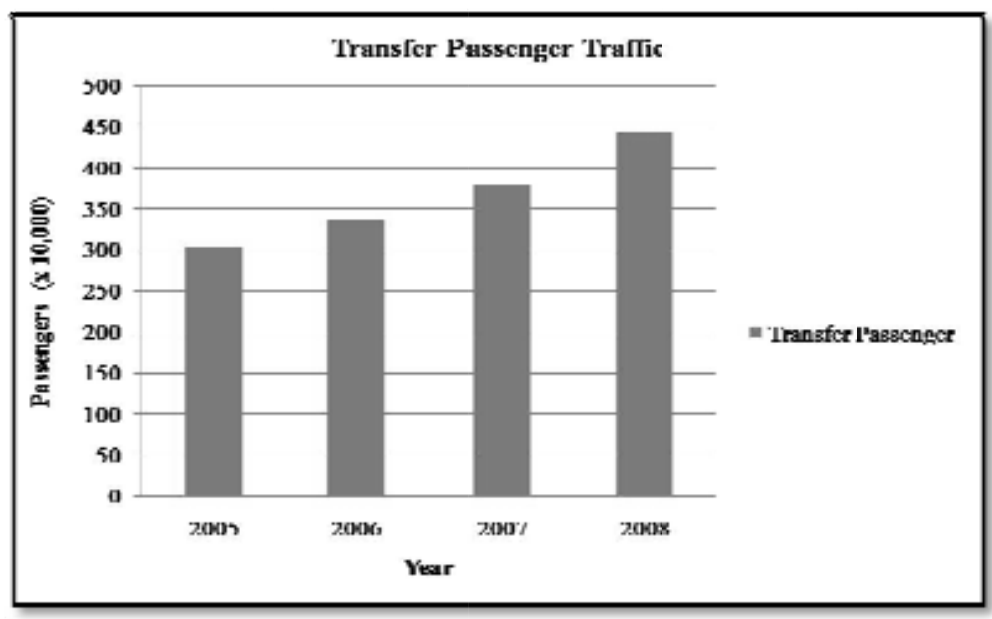

Figure 1. Transfer passenger traffic at Incheon International Airport

Incheon International Airport(IIA), which is considered the international gateway to South Korea. IIA has shown rate of increasing transfer passenger traffic. According to the results of annual report of IIA, the average daily transfer passenger were revealed that 3,050,000 transfer passengers used IIA in 2005, 3,360,000 transfer passengers used that in 2006, 3,790,000 transfer passengers used that in 2007 and passengers using transfer service of IIA are $4,420,000$ passengers. 


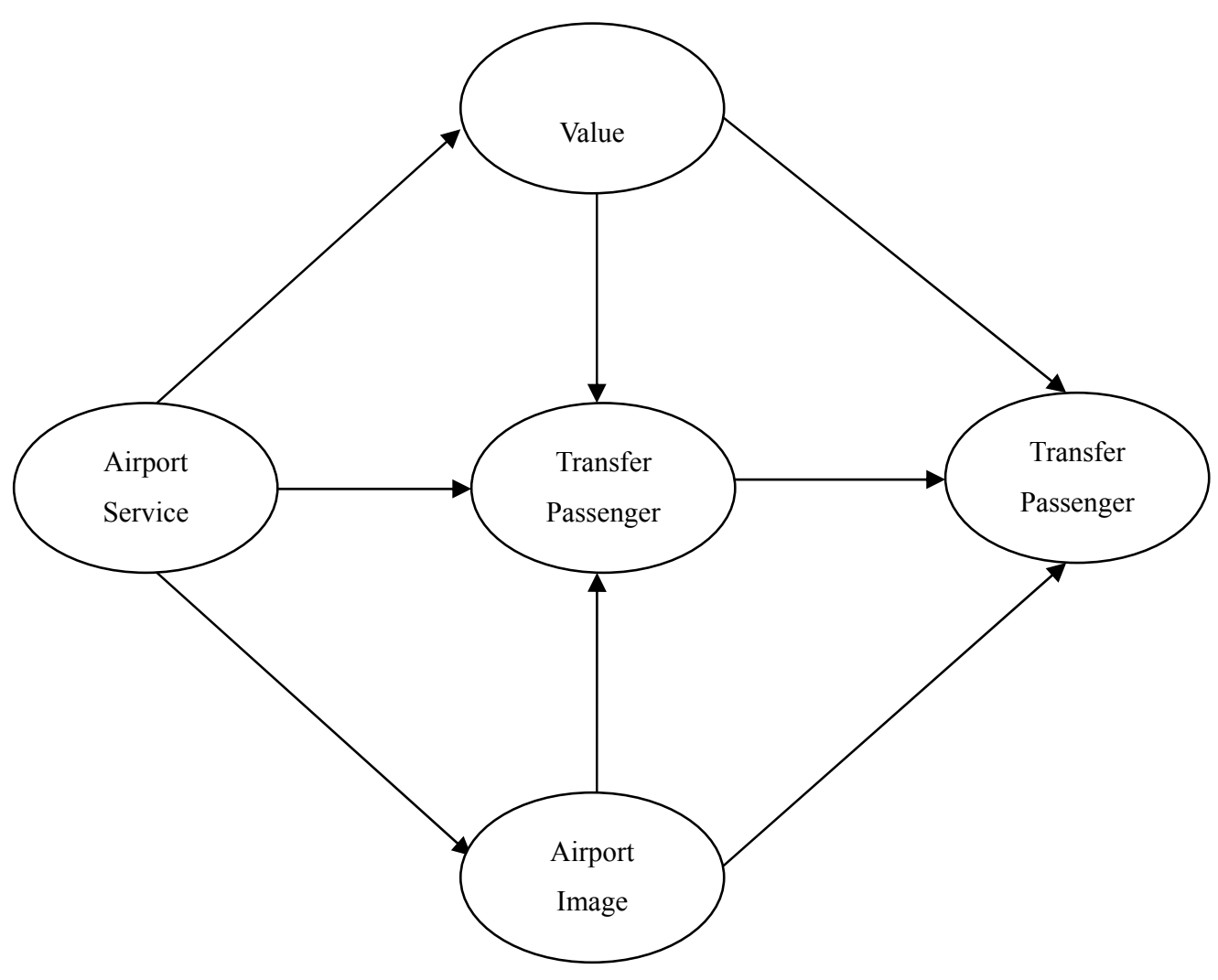

Figure 2. The conceptual model

To investigate transfer passenger's perception of airport service quality and its influence, the conceptual model has looked at airport service quality, value, transfer passenger satisfaction, airport image, and transfer passenger behavior. This paper proposes the following hypothesis:

Hypothesis 1, airport service quality is positively related to transfer passenger satisfaction.

Hypothesis 2, airport service quality is positively related to value.

Hypothesis 3, airport service quality is positively related to airport image.

Hypothesis 4 , value is positively related to transfer passenger satisfaction.

Hypothesis 5, airport is positively related to transfer passenger satisfaction.

Hypothesis 6, transfer passenger satisfaction is positively related to transfer passenger behavior.

Hypothesis 7 , value is positively related to transfer passenger behavior.

Hypothesis 8 , airport image is positively related to transfer passenger behavior. 


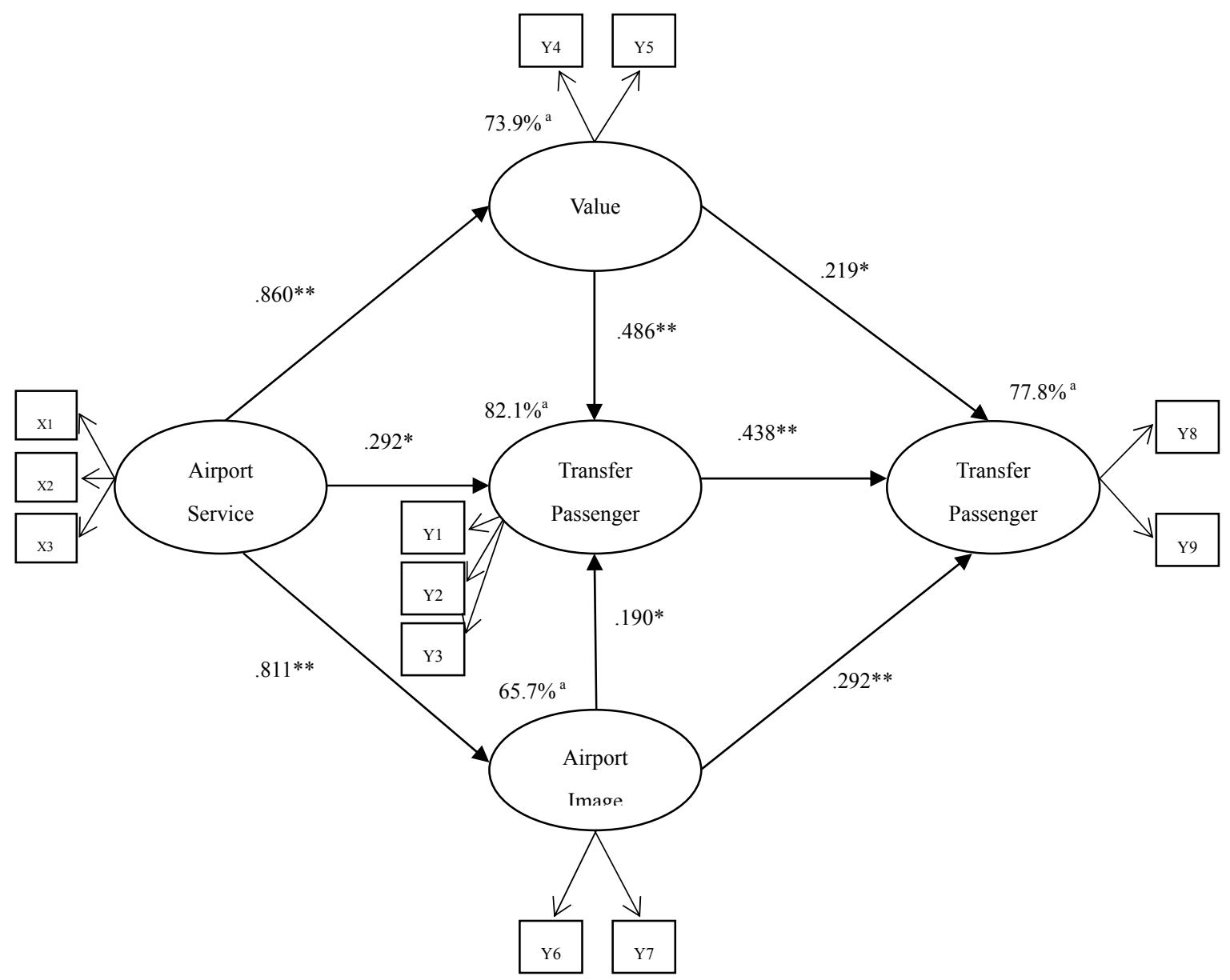

${ }^{a}$ The amount of variance explained

$* \mathrm{p}<0.05,{ }^{* *} \mathrm{p}<0.001$ level

Figure 3. Results of SEM analysis

The airport service quality, value, transfer passenger satisfaction, and airport image are each found to have a direct or indirect effect on transfer passenger behavior.

Hypothesis 1, airport service quality was found to be a significant factor in transfer passenger satisfaction $(\gamma=0.292$, $\rho<0.05$ ). Thus, $H_{1}$ was supported at the 0.05 level.

Hypothesis 2 , airport service quality was found to be a significant factor in value $(\gamma=0.860, \rho<0.001)$. Thus, $\mathrm{H}_{2}$ was supported at the 0.001 level.

Hypothesis 3, airport service quality was found to be a significant factor in airport image $(\gamma 0.811, \rho<0.001)$. Thus, $\mathrm{H}_{3}$ was supported at the 0.001 level.

Hypothesis 4 , value was found to be a significant factor in transfer passenger satisfaction $(\gamma=0.486, \rho<0.001)$. Thus, $\mathrm{H}_{4}$ was supported at the 0.001 level.

Hypothesis 5, airport image was found to be a significant factor in transfer passenger satisfaction $(\gamma=0.190, \rho<0.05)$. Thus, $\mathrm{H}_{5}$ was supported at the 0.05 level.

Hypothesis 6 , transfer passenger satisfaction was found to be a significant factor in transfer passenger behavior $(\mathrm{\gamma}$ $=0.438, \rho<0.001)$. Thus, $\mathrm{H}_{6}$ was supported at the 0.001 level.

Hypothesis 7 , value was found to be a significant factor in transfer passenger behavior $(\gamma=0.219, \rho<0.05)$. Thus, $\mathrm{H}_{7}$ was supported at the 0.05 level.

Hypothesis 8, airport image was found to be a significant factor in transfer passenger behavior $(\gamma=0.292, \rho<0.001)$. Thus, $\mathrm{H}_{6}$ was supported at the 0.001 level. 